\title{
Investigation of cranial and other nerves in the mouse with muscular dystrophy
}

\author{
T. J. BISCOE, K. W. T. CADDY, D. J. PALLOT, \\ AND U. M. M. PEHRSON ${ }^{1}$ \\ From the Department of Physiology, University of Bristol Medical School, Bristol
}

SYNOPSIS In the muscular dystrophic mouse mutant there is an absence of Schwann cells over circumscribed lengths of all cranial nerves except for II (I was not examined) and the lesion involves the sympathetic system. Where present, Schwann cells do not produce myelin of normal thickness. The lesion is similar to that described for the spinal roots. Causation is discussed.

Since the original description of the mouse mutant with muscular dystrophy by Michelson et al. (1955) there have been a number of studies which have shown neurological defects. A reduction in the number of myelinated fibres in peripheral nerves was described by Harris and Wilson (1971) and Harris et al. (1972). This reduction included the whole range of axon diameters and both sensory and motor systems so far as could be ascertained. The neuromuscular junction has also been studied by Ragab (1971) and Gilbert et al. (1973) who have shown a reduced number of synaptic vesicles many of which are irregular in shape.

Recently another lesion has been describednamely, an absence of Schwann cells over circumscribed lengths of the spinal nerve roots. Because of the absence of Schwann cells the nerve fibres are not myelinated though their axon diameters are often normal (Bradley and Jenkison, 1973; Salafsky and Stirling, 1973). We are interested in the neurological lesions which occur in behavioural mutants of the mouse and, in the case of the muscular dystrophic mutant, of the possible relationship between the neural lesion and the muscle defect. This problem has been a source of controversy for some years and, so far as the mouse is concerned the problem is unresolved (see, for example, Laird and Trimmer, 1965, 1966; Salafsky, 1971; Gallup and Dubowitz, 1973; Peacock and Nelson,

\footnotetext{
1 M.R.C. Scholar.

(Accepted 27 December 1974.)
}

1973). The objective of our work has been to determine how widespread the neural lesion is in the dystrophic mouse mutant and this paper gives an account of the structural defect in the cranial and some other nerves.

A short account of some of our results has been published (Biscoe et al., 1974).

\section{METHODS}

Homozygous dystrophic and normal $129 \mathrm{ReJ}$ mice aged 8 weeks and over were anaesthetized with sodium pentobarbitone $50-60 \mu \mathrm{g} / \mathrm{g}$ given intraperitoneally. The animals were perfused through the left ventricle with fixative sometimes preceded by $20 \mathrm{ml}$ $150 \mathrm{mM} \mathrm{NaCl}$ solution. The right auricle was opened to allow efflux of fluid. The fixatives used were $2.5 \%$ glutaraldehyde in cacodylate buffer or a glutaraldehyde/hydrogen peroxide mixture, as described by Perachia et al. (1970). The perfusion pressure was maintained at $220-240 \mathrm{mmHg}$ for $20-30$ minutes during which time $350-400 \mathrm{ml}$ of fixative flowed through the animals. During dissection tissues were kept moist with glutaraldehyde and after 2-12 hours in this primary fixative were post-fixed in $1 \%$ osmium tetroxide in cacodylate buffer for one hour. The tissue was stained en bloc in uranyl acetate followed by dehydration before embedding; in others thin sections were stained in uranyl acetate and lead citrate. Sections were examined and photographed with a Phillips EM300. Thick sections $(1 \mu \mathrm{m})$ were cut routinely with glass knives and stained with toluidine blue.

The following nerves were removed from both $d y / d y$ and $+/+$ mice: (1) cranial nerves II, III, IV, V, VI, VII, VIII, IX, X, XI, XII; (2) the pre- 


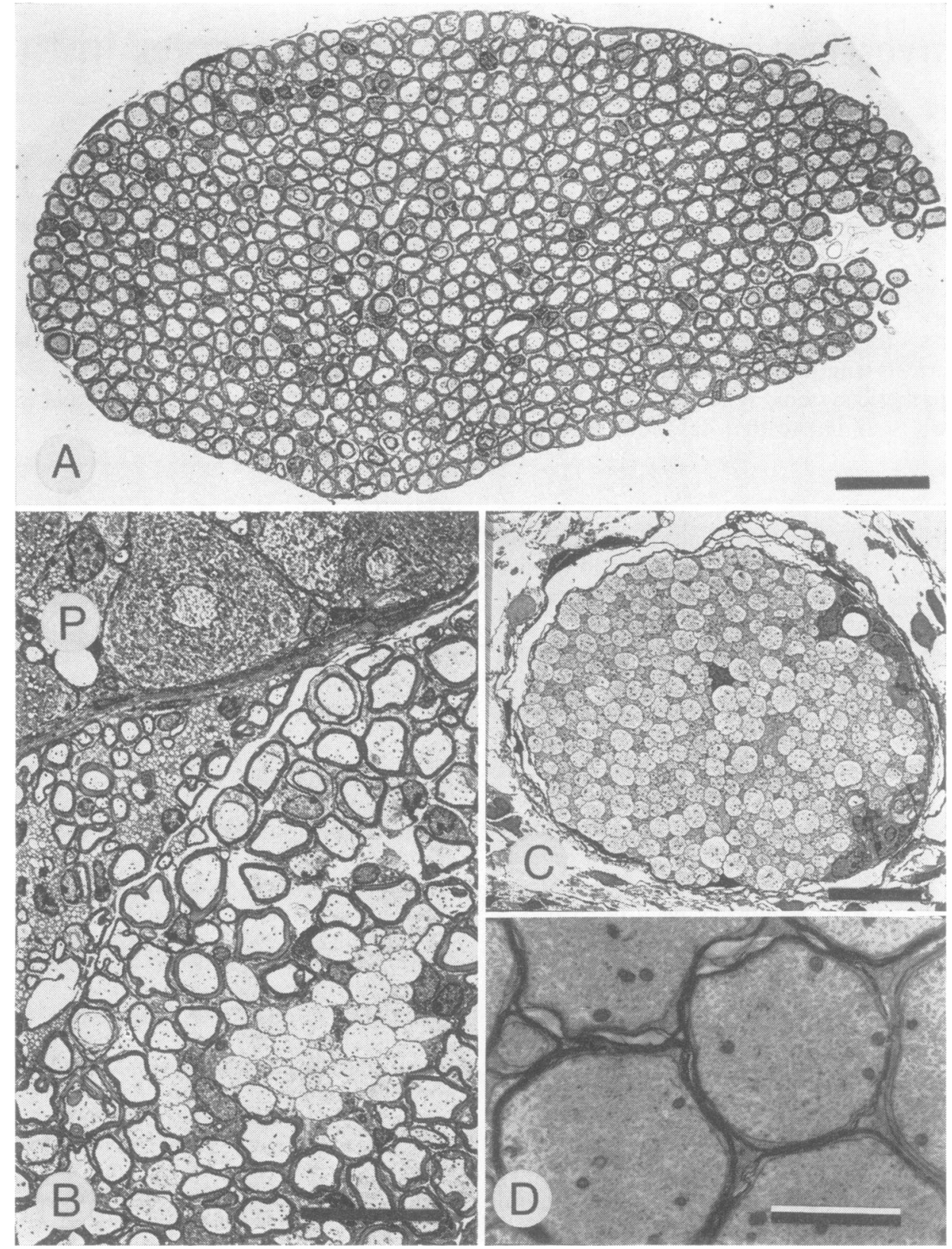

FIG. 1 Electron micrographs showing various degrees of severity of the neurological lesion in the dystrophic mouse compared with the normal mouse. A. IIIrd cranial nerve from a 12 week old normal mouse. $20 \mu \mathrm{m}$ bar. B. IX and Xth nerves from a 10 week old dystrophic mouse near the petrosal ganglion, cells of which can be seen in the upper part of the figure, P. An absence of Schwann cells is apparent in the middle of the Figure and affected fibres are scattered among the myelinated fibres. $20 \mu \mathrm{m}$ bar. C. IIIrd cranial nerve from an affected mouse of 10 weeks old (compare with A which is the same magnification) shows the gross difference in size between normal and dystrophic IIIrd nerve and also the very severe lesion compared with B. $20 \mu \mathrm{m}$ bar. D. Vth cranial nerve showing an intermediate form of the lesion. $2 \mu \mathrm{m}$ bar. 


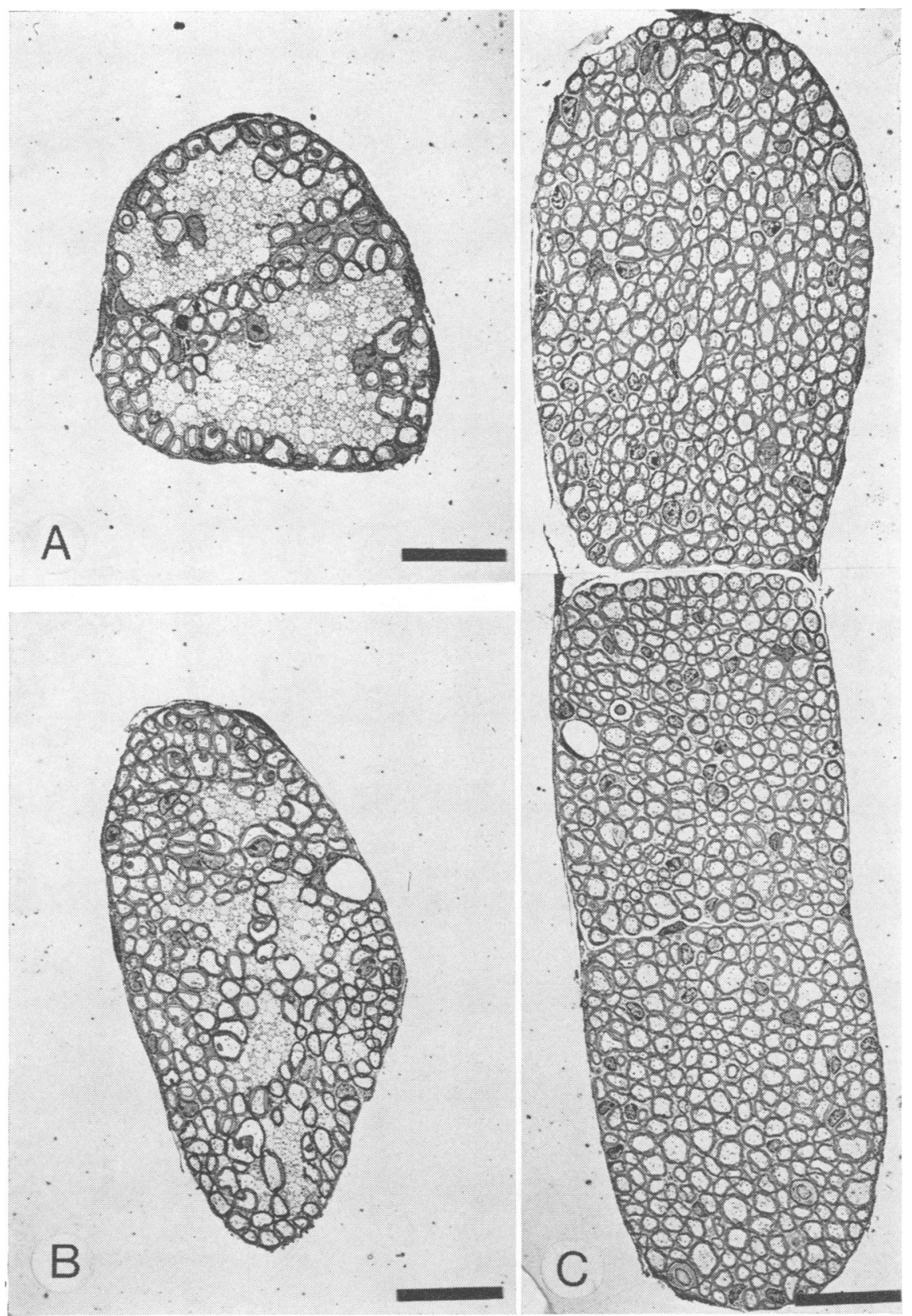

FIG. 2 Electron micrographs of two of the roots of the XIIth cranial nerve from dystrophic and normal mice. $\mathrm{A}$ and $\mathrm{B}$. The two major roots from an 8 week old dystrophic mouse show that $\mathrm{A}$ is more severely affected than B. $20 \mu \mathrm{m}$ bar. C. XIIth nerve from an 8 week old normal mouse compared with A and B shows the size disparity between dystrophic and normal nerves. $20 \mu \mathrm{m}$ bar. 


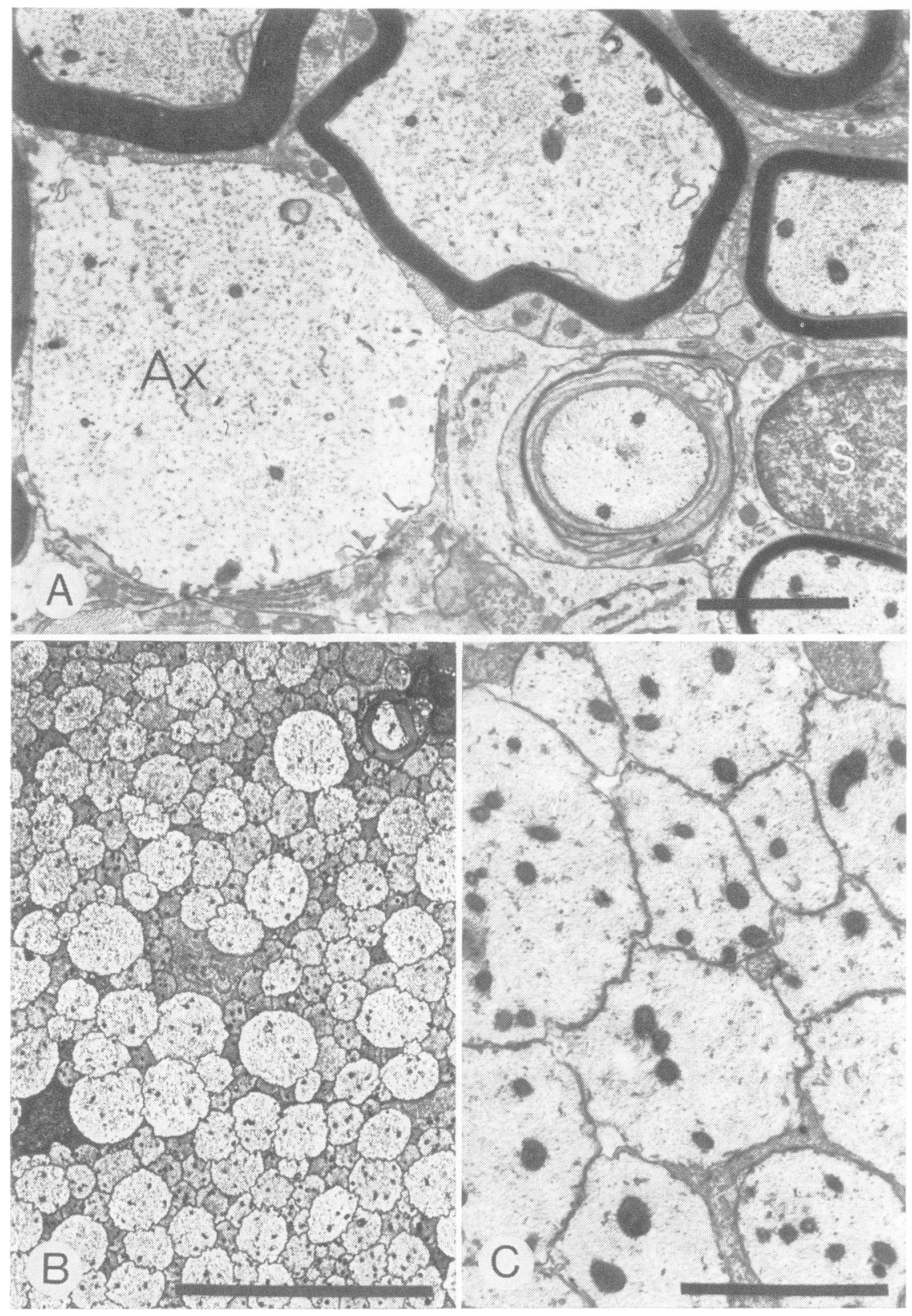

FIG. 3 Electron micrographs showing various degrees of severity of the neurological lesion in the dystrophic mouse. A. Extradural region of the VIth nerve from a 10 week old dystrophic mouse showing a range of myelin thicknesses in a number of nerve fibres. Schwann cells are present and a Schwann cell nucleus $(\mathbf{S})$ is shown. There is one very large axon (Ax) which has no myelin or Schwann cell around it. $2 \mu \mathrm{m}$ bar. B. An example of the most extreme form of the defect is shown in this section of a IIIrd cranial nerve from a 10 week old dystrophic mouse, taken near the CNS where there are tightly packed fibres with no surrounding Schwann cell. $20 \mu \mathrm{m}$ bar. C. Higher power view of VIth cranial nerve from an 8 week old dystrophic mouse. $2 \mu \mathrm{m}$ bar. 
ganglionic cervical sympathetic trunk for $2 \mathrm{~mm}$ below the superior cervical ganglion; (3) the cervical vagus nerve at the same level as (2); (4) the phrenic nerve immediately after formation from the cervical roots and also in the chest including the point of entry to the diaphragm.

In all cases specimens of cranial nerves were obtained which included the portion of central nervous system to which the nerve was attached. With nerves V, VIII, IX, X usually the entire course of the nerve as far distally as the sensory ganglion was fixed. With nerves VII, XI, XII the nerves were removed as far distally as the foramina through which they left the skull. Sometimes only the intracranial part of the II nerve was taken, at others the entire course up to and including the retina.

In the case of the nerves to the extraocular muscles (III, IV, VI) the dissection was extended to include the entire course of the nerve up to and including the muscle supplied. We gave particular attention to the VI nerve, since this, like IV, supplies only one muscle (the external rectus of the eye) but is easier to dissect along its entire course than IV. These three nerves thus have an intracranial intradural course, an intracranial extradural course, and an extracranial course. They are, therefore, exposed to cerebrospinal fluid along a part of their course only.

Axon diameters were measured from electronmicrographs of complete cross-sections of the nerve using a Zeiss particle size analyser. A magnification of $\times 1400$ was used for these measurements. The myelin thickness was measured directly from electron micrograph negatives taken at a magnification of $\times 2200$ and using a Bausch and Lomb measuring magnifier. The thickness was measured at two opposite points on each fibre where the laminae were parallel and undisturbed by fixation artefacts.

\section{RESULTS}

The mice with muscular dystrophy in our colony are generally smaller than the wild type and the normal heterozygotes. We do not know whether this difference is due to nutritional difficulties associated with muscular weakness, or whether there is some other genetic cause. Usually we have examined the larger animals whose weights overlap the range of the normal, though we have also studied severely affected animals. We have noted no important qualitative differences among the group of affected mice.

QUALITATIVE RESULTS Macroscopic observations When the cranium of the dystrophic mouse is removed and the cerebral cortex excised the neuropathological lesion is usually obvious. The trigeminal nerve and the optic nerve are the two most striking features on the floor of the anterior fossa; the former is usually a grey colour and the latter is glistening white. This difference in colour is not so obvious as that between the dystrophic mouse lumbar spinal dorsal roots and the cord dorsum but is nevertheless marked.

Another difference at the macroscopic level is the relative size of the nerves. They are invariably smaller in the $d y / d y$ mutant than normal and this difference can be recognized under an operating microscope at $\times 20$ magnification. It is clearly shown in the transverse sections of Fig. 1A, C for III and Fig. 2 for XII.

Microscopic observations Thick sections were used primarily to orient blocks correctly so that transverse or longitudinal sections could be cut for electron microscopy. However, some of the nerves could be identified as pathological when stained with toluidine blue, especially those which show gross lesions as in Fig. 1C. Nevertheless, only in the electron microscope with its superior resolution could the lesion be defined accurately.

Various degrees of severity of the lesion are depicted in Fig. 3. In Fig. 3A, taken from the VIth nerve a range of myelin thicknesses can be seen for a number of nerve fibres. In most of these examples the myelin is abnormally thin, though Schwann cells are present and a Schwann cell nucleus $(\mathbf{S})$ is shown. There is one very large axon (Ax) which has no myelin or Schwann cell around it.

Examples of the most extreme form of the defect are shown in Fig. 3B, C where tightly packed fibres with no surrounding Schwann cell are seen. This remarkable appearance is the same as that described in the spinal roots by Bradley and Jenkison (1973) and Stirling (1975).

The defect was found in all nerves studied except for II and the phrenic nerve. The most extreme forms are seen in the nerves to the external ocular muscles. Figure $1 \mathrm{C}$ shows a section from the intracranial, extradural part of the IIIrd nerve, and a very severe lesion is also shown for the VIth nerve in Fig. 3B of Biscoe et al. (1974). Figure 1C should be compared with Fig. 1A which shows a III nerve from the normal 


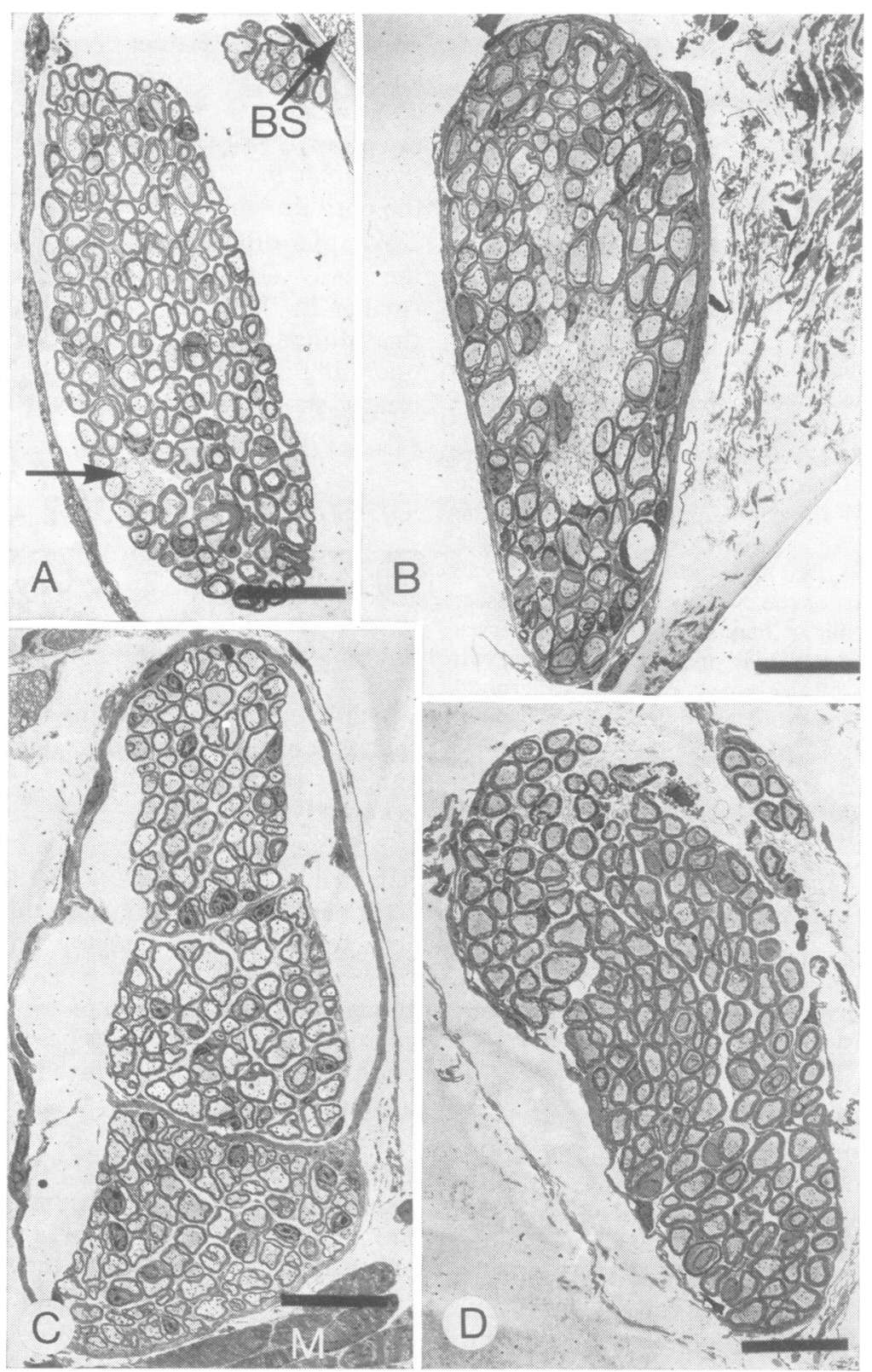

FIG. 4 Electron micrographs show how the lesion in the VIth cranial nerve from an 8 week old dystrophic mouse changes along the course of the nerve from brain stem to muscle and compares it with the normal nerve. A. This section is less than $50 \mu \mathrm{m}$ from the brain-stem, a part of which is seen in the top right hand corner of the picture (BS). A few axons are free of myelin (arrow) while the remaining myelin is much thinner than normal (compare with normal nerve in D). $20 \mu m$ bar. B. Moderately severe form of the lesion about halfway between brain-stem and muscle (about $4 \mathrm{~mm}$ from brain-stem). $20 \mu \mathrm{m}$ bar. C. Near the external rectus muscle (M) there are no fibres without myelin but the myelin present is very much thinner than normal. $20 \mu \mathrm{m}$ bar. D. Normal nerve from 13 week old homozygous normal mouse; section taken less than $100 \mu \mathrm{m}$ from brain-stem. $20 \mu \mathrm{m}$ bar. 

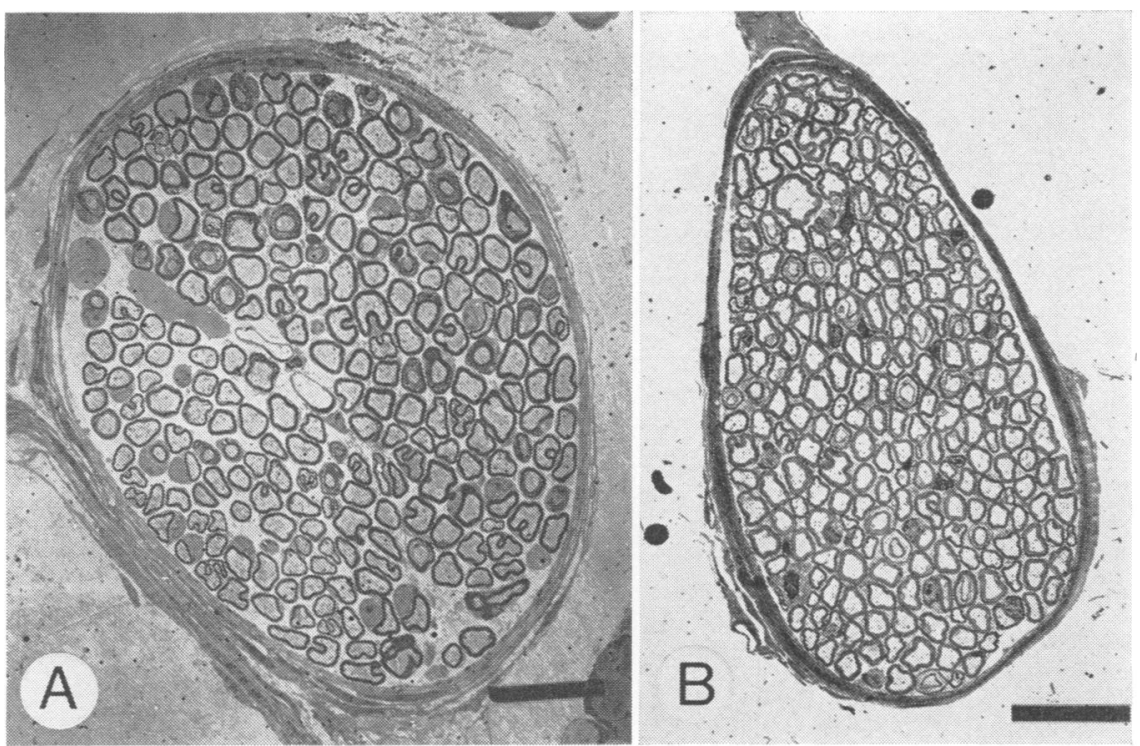

FIG. 5 Electron micrographs comparing phrenic nerves of dystrophic and normal mice. A. Phrenic nerve from a 14 week old dystrophic mouse showing thinner than normal myelin but no fibres without myelin. 20 um bar. B. Phrenic nerve from an 8 week old normal mouse for comparison with A. $20 \mu \mathrm{m}$ bar.

$129 \mathrm{ReJ}$ mouse; the gross disparity in size has already been mentioned.

That the defect is not always so severe as this is shown in Fig. 4B where the VIth nerve is only partly lacking in Schwann cells, though it is clear that the myelin is generally thinner than normal (compare Fig. 4B, C with D). Such a picture is more typical of the cranial nerves as a group and in some cases the lesion may be found only after a careful search. For example, Fig. 1B shows a section from the IX and Xth nerves near the petrosal ganglion, cells of which can be seen in the upper part of the figure. An absence of Schwann cells can be noted about the middle of the figure and groups of affected fibres are scattered among the myelinated fibres. A similar appearance is found in V, VII, VIII, and XI, though in our series XII was often more severely affected than these nerves. In Fig. 2 sections of the two major roots of XII are compared for dystrophic, A, B, and normal, C. The upper root, in A is markedly affected, the lower root, B, less so. Again the size disparity between dystrophic and normal is clear.

In many cases intermediate forms of the lesion can also be seen as in the VIth nerve of Fig. 3A and in the Vth nerve of Fig. 1D which shows fibres having abnormally thin myelin. The myelin of Fig. 1D has some of the appearances of central myelin and is similar to that found by Bradley and Jenkison (1973) in the spinal roots of dystrophic mice. We were unable to see a basal lamina but do not regard this as conclusive evidence for a central origin, since the fibres were so tightly packed that our view was obscured. Often the difference in the myelin between normal and dystrophic mouse is less obvious and only shows up after systematic measurements have been taken (see below).

EXTENT OF LESION IN CRANIAL NERVE We found the VIth nerve the easiest in which to study changes in the lesion with changes in distance from the central nervous system, though the results were confirmed on the other cranial nerves. This nerve is the best because of the changing nature of its course and because it supplies only one muscle as mentioned above. A complete abducent (VI) nerve including brainstem and external rectus muscle was dissected from five dystrophic mice and four normal mice. Thin sections were examined at every $100 \mu \mathrm{m}$ of 


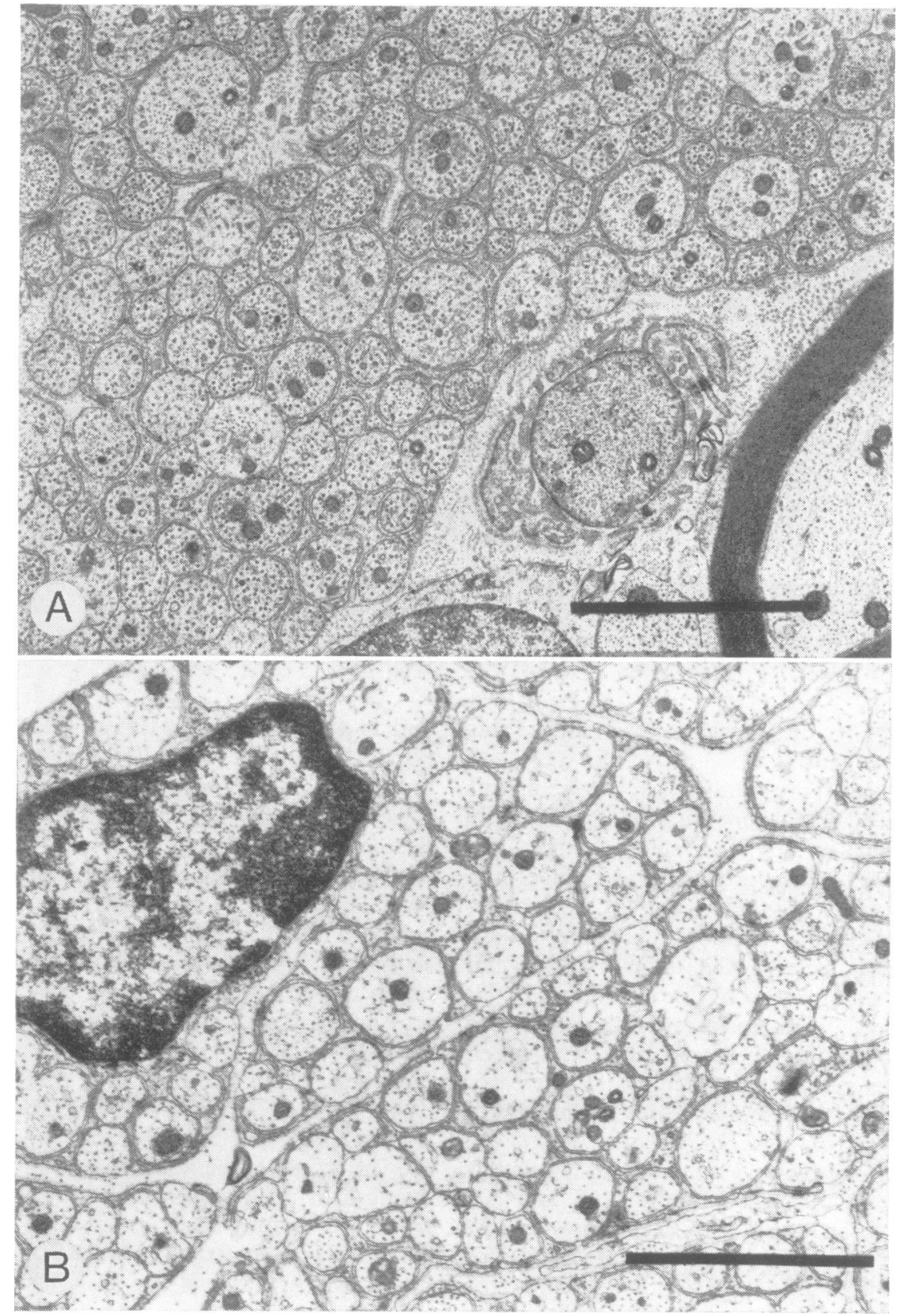

FIG. 6 Electron micrographs of post-ganglionic sympathetic branch of the carotid plexus from 8 week old dystrophic and normal mice. A. Affected nerve showing a paucity of Schwann cell cytoplasm and few Schwann cell nests. $2 \mu \mathrm{m}$ bar. B. Normal nerve shows a greater number of Schwann cell nests and more extensive Schwann cell processes than in the mutant. $2 \mu \mathrm{m}$ bar. 
the entire course. Representative examples of the manner in which the lesion changes are shown in Fig. 4A-C. In Fig. 4A the section was taken a very short distance $(<50 \mu \mathrm{m})$ from the brain-stem, a part of which is included in the top right hand corner of the picture; a few axons are free of myelin (arrow) while the remaining myelin is thinner than normal (compare Fig. 4D). All of the cells enclosing myelinated fibres at this level show basal laminae and are therefore regarded as Schwann cells; thus the myelination at this point is not produced by extensions of oligodendrocytes. The section of Fig. 4B was taken approximately $4 \mathrm{~mm}$ from the central nervous system and shows a typical moderately severe form of the lesion. Absence of myelination such as this was usually present over a distance of less than $50 \mu \mathrm{m}$ to about $4 \mathrm{~mm}$ from the brain-stem. At greater distances from the brain-stem all axons were myelinated, though the myelin remained abnormally thin as shown in Fig. 4C. This section was taken near the external rectus muscle, a part of which is shown at the lower edge of the micrograph. Figure 4D is a micrograph of a normal abducent nerve for comparison taken $100 \mu \mathrm{m}$ from the brain-stem, a level at which the lesion would be expected to be present in the dystrophic animal.

The conclusion is that near the central nervous system cranial nerves generally have a normal appearance with respect to the presence of myelination. Some $100 \mu \mathrm{m}$ from the CNS some axons will be found which lack myelin (except II and VIII) and do so for a distance which varies with the particular nerve though at the point of exit from the skull the nerve is usually myelinated.

PHRENIC NERVE We found no evidence for an absence of myelination in this nerve (see Fig. 5A, B), though Stirling (1975) has shown that the cervical spinal roots are affected.

CERVICAL SYMPATHETIC NERVE The most striking difference between nerves of the normal and the dystrophic mouse was size disparity, the nerve in the dystrophic animal usually being one-half to one-third the diameter of the normal. There was no evidence for an absence of Schwann cells in our material. However, there is a post-ganglionic sympathetic branch of the carotid plexus that
TABLE 1

NUMBER OF AXONS AND MEAN FIBRE DIAMETERS IN SOME WILD TYPE AND DYSTROPHIC MOUSE MUTANT CRANIAL NERVES

\begin{tabular}{|c|c|c|c|c|}
\hline \multirow[t]{2}{*}{ Nerve } & \multicolumn{2}{|c|}{$+1+$} & \multicolumn{2}{|c|}{$d y / d y$} \\
\hline & $\begin{array}{c}\text { Axons } \\
\text { (no.) }\end{array}$ & $\begin{array}{c}\text { Mean } \\
\text { diameter } \\
(\mu m)\end{array}$ & $\begin{array}{l}\text { Axons } \\
\text { (no.) }\end{array}$ & $\begin{array}{c}\text { Mean } \\
\text { diameter } \\
(\mu m)\end{array}$ \\
\hline \multirow[t]{2}{*}{ III } & 691 & 2.36 & $\left.\begin{array}{c}102 \\
80\end{array}\right\}$ & $\left.\begin{array}{l}2.52 \\
1.64\end{array}\right\}$ \\
\hline & 679 (Fig. 1A) & 2.24 & 605 (Fig. 1C) & 1.96 \\
\hline IV & 304 & 2.79 & 112 & 2.34 \\
\hline \multirow[t]{4}{*}{ VI } & $\begin{array}{l}340 \\
171 \text { (Fig. 4D) }\end{array}$ & $\begin{array}{l}2.50 \\
1.94\end{array}$ & $\left.\begin{array}{c}107 \\
53\end{array}\right\}$ & $\left.\begin{array}{l}2.30 \\
1.71\end{array}\right\}$ \\
\hline & 153 & 2.38 & $\left.\begin{array}{r}55 \\
123\end{array}\right\}$ & $\left.\begin{array}{l}2.22 \\
2.39\end{array}\right\}$ \\
\hline & 150 & 2.13 & $\left.\begin{array}{r}20 \\
661\end{array}\right\}$ & $\left.\begin{array}{l}1.95 \\
1.44\end{array}\right\}$ \\
\hline & & & $\left.\begin{array}{c}108 \\
77\end{array}\right\}^{(\text {Fig. 4B) }}$ & $\left.\begin{array}{l}2.23 \\
2.31\end{array}\right\}$ \\
\hline XI & 389 & 1.88 & $\left.\begin{array}{r}237 \\
82 \\
94\end{array}\right\}$ & $\left.\begin{array}{l}2.79 \\
1.69 \\
0.55\end{array}\right\}$ \\
\hline \multirow[t]{2}{*}{ XII } & 170 & 2.15 & $\left.\begin{array}{l}185 \\
397\end{array}\right\}$ & $\left.\begin{array}{l}1.97) \\
1.45\end{array}\right\}$ \\
\hline & 859 (Fig. 2C) & 1.73 & $\left.{ }_{724}^{301}\right\}^{\text {(Fig. 2A) }}$ & $\left.\begin{array}{l}1.74 \\
1.40\end{array}\right\}$ \\
\hline
\end{tabular}

Numbers in italic type refer to nerve fibres without Schwann cells. Numbers in bold type refer to non-myelinated fibres (with Schwann cell)

Parentheses indicate measurements from one nerve.

joins the VI nerve before this nerve leaves the anterior fossa of the skull; this nerve was affected. An example of this nerve from a dystrophic mouse is shown in Fig. 6A and is to be compared with the normal of Fig. 6B. The micrographs show that there are many fewer Schwann cell nests in $A$ than $B$ and that the Schwann cell processes are not so extensive in the mutant. The lesion is not at all pronounced (compare for example Fig. 3B) but was consistently present in this form.

QUANTITATIVE RESULTS Measurements of axon diameter and myelin thickness have been made on examples of nerves III, IV, VI, IX, X, XI, and XII.

Number of axons The results are summarized in Table 1 where it can be seen that, although in some cases fewer axons are present in the $d y$ 

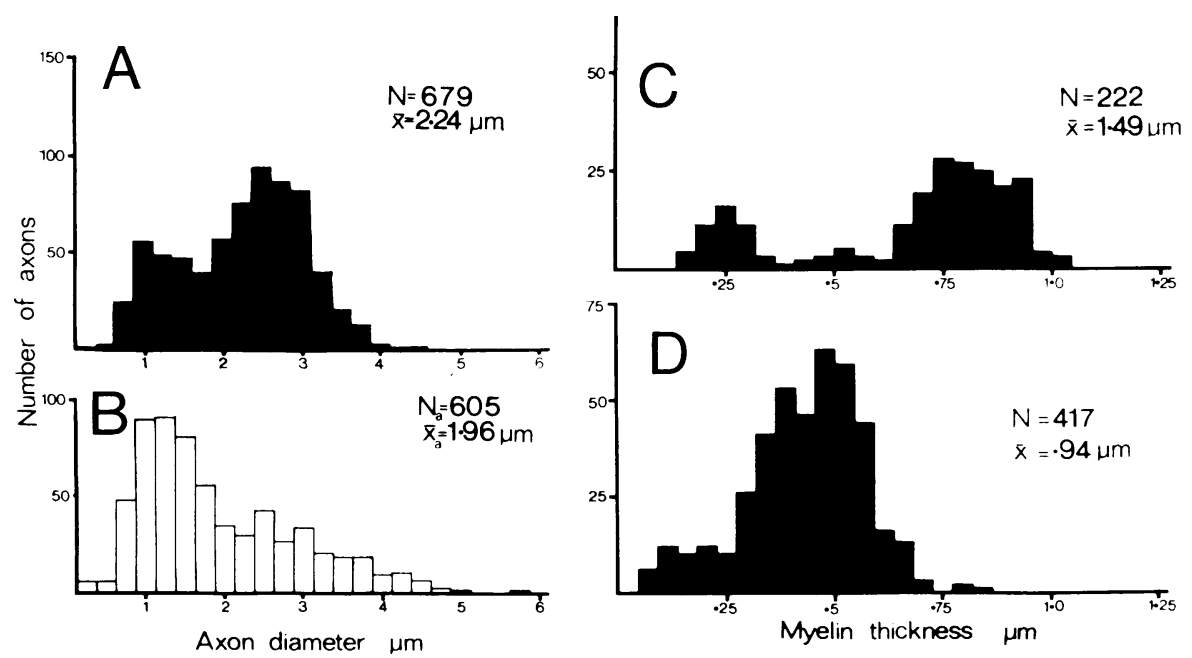

FIG. 7 Quantitative results from measurements made on the IIIrd cranial nerves of normal and dystrophic mice. A. Histogram showing frequency distribution of axon diameters in a normal 8 week old mouse. B. Histogram (to be compared with A) showing frequency distribution of axon diameters in a dystrophic 8 week old mouse. C. Myelin thickness histogram in a normal 12 week old mouse. D. Myelin thickness histogram from a dystrophic 12 week old mouse (compare with $\mathrm{C}$ ). Key: $\mathrm{N}=$ number of myelinated axons measured. $\mathrm{N}_{\mathrm{a}}=$ number of amyelinated axons measured. $\overline{\mathrm{x}}=$ mean axon diameter or myelin thickness in myelinated fibres. $\overline{\mathrm{x}}_{\mathrm{a}}=$ mean axon diameter of amyelinated fibres. $\mathbf{\square}=$ myelinated fibres. $\square=$ amyelinated fibres .

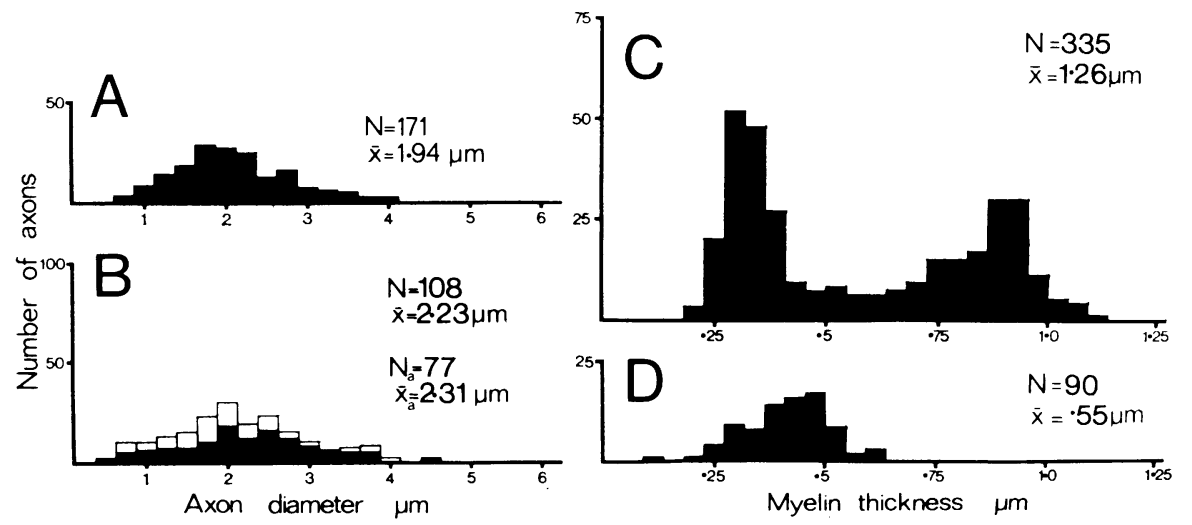

FIG. 8 Quantitative results from measurements made on the VIth cranial nerves from normal and dystrophic mice. A. Axon diameter histogram from a 13 week old normal mouse. B. Axon diameter histogram from a 12 week old dystrophic mouse. C. Myelin thickness histogram from a 12 week old normal mouse. D. Myelin thickness histogram from an 8 week old dystrophic mouse. Key same as for Fig. 7.

mutant than in normal nerves, this is not a consistent finding.

Mean diameter The results in Table 1 show that the mean axon diameter for myelinated fibres is in general similar in the two groups, though the fibres lacking Schwann cells are usually smaller than those of the wild type. That this is not always so is shown by two of the samples of VIth nerve.

Myelin thickness The measurements of Table 2 were taken from all fibres which showed good myelin fixation and are to that extent selected. 

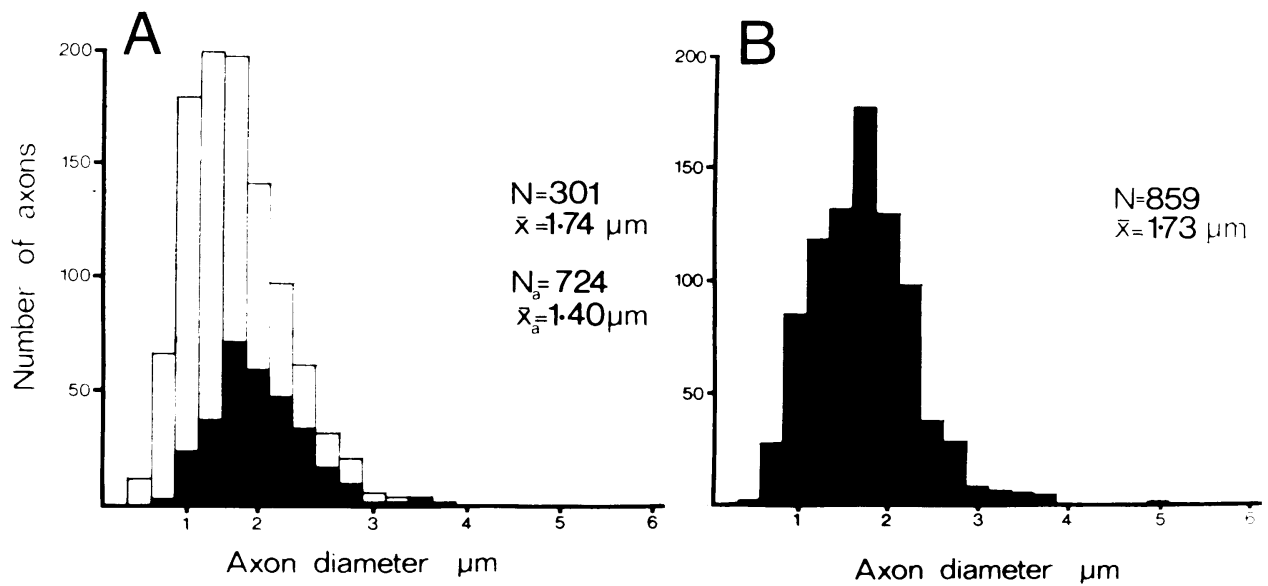

FIG. 9 Axon diameter histograms from measurements made on the XIIth cranial nerces from normal and distrophic mice. A. Histogram for dystrophic 8 week old mouse. B. Histogram for normal 8 week old mouse. Key same as for Fig. 7.

TABLE 2

MEAX MYELIN THICKNESS AND NLMBER OF MEASUREMENTS MADE ON A NLMBER OF CRANIAL NERVES FROM WILD TYPE AND DYSTROPHIC MOLSE MUTANT*

\begin{tabular}{|c|c|c|c|c|}
\hline \multirow[t]{2}{*}{ Viree } & \multicolumn{2}{|c|}{$-1+$} & \multicolumn{2}{|c|}{$d_{y} \cdot d y$} \\
\hline & $\begin{array}{l}\text { Fibres } \\
\text { measured } \\
\text { (no.) }\end{array}$ & $\begin{array}{l}\text { Myelin } \\
\text { thickness } \\
\text { (:mm) }\end{array}$ & $\begin{array}{l}\text { Fibre's } \\
\text { measured } \\
\text { (no.) }\end{array}$ & $\begin{array}{l}\text { Myelin } \\
\text { thickness } \\
(: 2 m)\end{array}$ \\
\hline 111 & 222 & 1.49 & 417 & 0.94 \\
\hline IV & $\begin{array}{l}110 \\
177\end{array}$ & $\begin{array}{l}0.72 \\
0.68\end{array}$ & 113 & 0.46 \\
\hline VI & $\begin{array}{l}338 \\
335\end{array}$ & $\begin{array}{l}1.23 \\
1.26\end{array}$ & $\begin{array}{r}20 \\
130 \\
170 \\
90 \\
63\end{array}$ & $\begin{array}{l}0.41 \\
0.63 \\
0.54 \\
0.55 \\
0.54\end{array}$ \\
\hline IX, X & 291 & 0.75 & 298 & 0.58 \\
\hline XI & $\begin{array}{l}142 \\
236\end{array}$ & $\begin{array}{l}0.64 \\
0.75\end{array}$ & $\begin{array}{l}211 \\
211\end{array}$ & $\begin{array}{l}0.50 \\
0.54\end{array}$ \\
\hline XII & $\begin{array}{r}80 \\
110\end{array}$ & $\begin{array}{l}0.54 \\
0.71\end{array}$ & $\begin{array}{l}142 \\
281\end{array}$ & $\begin{array}{l}0.42 \\
0.43\end{array}$ \\
\hline
\end{tabular}

* Not all fibres were measured.

They show that in the $d y$ mutant the total thickness of the myelin, when present. is always less than in the normal mouse. This confirms the impression gained from viewing the electron micrographs, see especially Fig. 4.

Particular examples of the distributions of axon diameters and myelin thickness are shown in the accompanying Figures, which compare results from normal and dystrophic mice. Results for III, VI, and XII in Figs 7, 8, and 9 respectively show that the distributions of axon diameter overlap and that when Schwann cells are absent the fibre diameters usually fall into spectra similar to those of the myelinated fibres (Figs 8 and 9). In some cases there may appear to be a shift as with the IIIrd nerve of Fig. 7, though here there is no internal comparison with myelinated fibres, only with a nerve from the normal. More interestingly, the myelin thickness histograms of Figs 7 and 8 show that in the nerves from the mutant the myelin tends to assume a more uniform thickness as shown by the absence of a bimodal distribution.

\section{DISCUSSION}

The results show that in the dystrophic mutant there is an absence of Schwann cells over discrete regions of all the cranial nerves excepting I which we have not examined and II which is unaffected. In addition, sympathetic nerves may be affected.

Also, where Schwann cells are present they appear to be incapable of producing a myelin of normal thickness. These findings are similar to those of Bradley and Jenkison (1973) who first described these lesions in the spinal roots and 
their results have been confirmed by Salafsky and Stirling (1973) and Stirling (1975).

The question arises as to why there is a smaller number of Schwann cells present than normal. There seem to be a number of possible reasons for this:

1. The Schwann cells may simply be missing during development either (a) because there is a neural crest lesion, or (b) because at some stage in development they degenerate.

2. The Schwann cell precursors may be present in the neural crest but not functioning correctly because, (a) they migrate to the wrong place, (b) they migrate at the wrong time and arrive in the wrong place, (c) they migrate to the right place but cease to divide, (d) they migrate to the right place but do not attach to the axon.

We doubt that this list includes all possibilities and the reasons are not mutually exclusive. It seems clear that the problem would be clarified by studying the development of the lesions. In the first place examination of the morphology of the embryo and newborn could show whether or not the neural crest was intact or degeneration occurred. The study of errors in migration is more difficult but a combination of morphological and autoradiographic experiments should show what is happening. At present we think that degeneration is unlikely to explain the appearance of the nerves, since we find no residuum of myelin fragments in animals only 4-5 weeks old and would expect to do so in such a case (Nathaniel and Pearse, 1963). Underlying most of these possible causes is a disorder of migration and if this should prove to be the basic fault then the lesion falls into line with the errors of migration described for other mouse mutants - for example, weaver by Rakic and Sidman (1973).

One can argue further that errors of migration probably represent errors of timing in the issuing of instructions and such errors may be a fundamental cause of some neurological disorders.

It is interesting that we found no convincing evidence of an absence of Schwann cells in the cervical sympathetic nerve but did find that a branch of the carotid plexus was involved. Since such a branch is even further from the CNS than the cervical sympathetic the lesion is unusual. It appears, then, that there is some importance attaching to the intracranial position of the nerve and perhaps also this relates to the origin of the Schwann cells normally involved.

Lastly, of considerable importance to the⿳亠丷厂 functioning of the $d y / d y$ nervous system are the $e_{0}^{D}$ physiological consequences of the lesion. We have begun to explore these with neurophysiological and neuropharmacological methods but it seems certain that the imposition of a length $\overrightarrow{\vec{F}}$ of non-myelinated nerve in a pathway that is normally myelinated will lead to disorganization? of both sensory and motor information. Much $\frac{\bar{\sigma}}{\bar{N}}$ depends upon how nerve impulses travel across $\overrightarrow{\mathrm{D}}$ the non-myelinated region. If they are conducted, then there will be an increase in temporal dispersion which will render the information. abnormal. If they are not conducted but there is $\vec{\omega}$ electrotonic spread of the impulse across the gap, there would be spatial as well as temporal dispersion of the information. Thus, impulses? from one modality might be transferred to another or from one muscle nerve to another. $\stackrel{\vec{\omega}}{\mathrm{\omega}}$ This could happen also if there were ephaptic $\stackrel{\Theta}{-}$ transmission between the fibres at the site of the 9 lesion, which is a distinct possibility. Whether or not there is transmission across the gap electro- $\frac{7}{5}$ tonically will be determined by the magnitude of the length constant for the whole nerve, and $\overrightarrow{\mathrm{c}} \cdot \overrightarrow{\mathrm{C}}$ any case if it is unusual it will affect the way which the whole structure performs as a transmission line.

In conclusion, the further elucidation of the causes of this lesion should come from develop- 0 mental studies. To undertake these one requires $\propto$ known homozygous $d y$ mutants before the $\overrightarrow{\overrightarrow{0}}$ phenotype is recognizable. There are difficulties 3 in producing these when the Mendelian gene is an autosomal recessive and the animals do not breed well. It is in this direction that our work is proceeding.

We wish to thank the Wellcome Trust for a grant for purchase of the E.M. 300 and ancillary equipment.

\section{REFERENCES}

Biscoe, T. J., Caddy, K. W. T., Pallot, D. J., Pehrson, N U. M. M., and Stirling, C. A. (1974). The neurological o lesion in the dystrophic mouse. Brain Research, 76, 534- N 536.

Bradley, W. G., and Jenkison, M. (1973). Abnormalities of peripheral nerves in murine muscular dystrophy. Journal $<$ of the Neurological Sciences, 18, 227-247. 
Gallup, B., and Dubowitz, V. (1973). Failure of 'dystrophic' neurones to support functional regeneration of normal or dystrophic muscle in culture. Nature, 243, 287-289.

Gilbert, J. J., Steinberg, M. C., and Banker, B. Q. (1973). Ultrastructural alterations of the motor end plate in myotonic dystrophy of the mouse $\left(d y^{2 \mathrm{j}} / d y^{2 \mathrm{j}}\right)$. Journal of Neuropathology and Experimental Neurology, 32, 345-364.

Harris, J. B., Wallace, C., and Wing, J. (1972). Myelinated nerve fibre counts in the nerves of normal and dystrophic mouse muscle. Journal of the Neurological Sciences, 15, 245-249.

Harris, J., and Wilson, P. (1971). Denervation in murine dystrophy. Nature, 229, 61-62.

Laird, J. L., and Timmer, R. F. (1965). Homotransplantation of dystrophic and normal muscle. Archives of Pathology and Laboratory Medicine, 80, 442-446.

Laird, J. L., and Timmer, R. F. (1966). Transplantation of skeletal muscle into a host with muscular dystrophy. Texas Reports on Biology and Medicine, 24, 169-179.

Michelson,, A. M., Russell, E. S., and Harman, P. J. (1955). Dystrophia muscularis: a hereditary form of myopathy in the house mouse. Proceedings of the National Academy of Science, U.S.A., 41, 1079-1084.

Nathaniel, E. J. H., and Pease, D. C. (1963). Degenerative changes in rat dorsal roots during Wallerian degeneration. Journal of Ultrastructural Research, 9, 511-532.

Peacock, J. H., and Nelson, P. G. (1973). Synaptogenesis in cell cultures of neurones and myotubes from chickens with muscular dystrophy. Journal of Neurology, Neurosurgery, and Psychiatry, 36, 389-398.

Peracchia, C., and Mittler, B. G. (1972). Fixation by means of glutaraldehyde-hydrogen peroxide reaction products. Journal of Cell Biology, 53, 234-238.

Ragab, A. H. M. F. (1971). Motor-end-plate changes in mouse muscular dystrophy. Lancet, 2, 815-816.

Rakic, P., and Sidman, T. L. (1973). Weaver mutant mouse cerebellum; defective neuronal migration secondary to abnormality of Bergmann glia. Proceedings of the National Academy of Sciences of the United States of America, 70, 240-244.

Salafsky, B. (1971). Functional studies of regenerated muscles from normal and dystrophic mice. Nature, 229, 270-272.

Salafsky, B., and Stirling, C. A. (1973). Altered neural protein in murine muscular dystrophy. Nature New Biology, 246, 126-128.

Stirling, C. A. (1975). Abnormalities in Schwann cell sheaths in spinal nerve roots of dystrophic mice. Journal of Anatomy, 119, 169-180. 